\title{
Acumulação e desestabilização da forma na narrativa brasileira atual
}

\section{Andrea Saad Hossne}

\begin{abstract}
Resumo: Na líteratura do fim do século xx e inicio do xxr, observa-se, em geral, uma produção de textos avessos a classificaçỏes e pouco adequados às categorias formais pertencentes à tradiçăo. Diante de O fluxo silencioso das máquinas, de Bruno Zeni, Curva de rio sujo, de Joca Reiners Terron, e Eles eram muitos cavalos, de Luiz Ruffato, o critico se vê às voltas com o problema da definição do gênero a que se filiam. Classificar ou não essas obras é uma dificuldade berm menos importante que o dilema que elas formalizam ou encenam: a de estabelecer relaçóes, conferir sentido, ter, senào a totalidade, ao menos o impulso de buscá-la. Palavras-chave; Bruno Zeni, Joca Reiners Terron, Luiz Ruffato.
\end{abstract}

\footnotetext{
Abstract: In the literature of the end of the $\mathrm{xx}$ century and beginning of the $\mathrm{xx}$, a production of texts averse to classification and little adequate to formal categories belonging to tradition is generally observed. Before O Fluxo Silencioso das Maquinas, by Brino Zeni, Curva de Rio Sujo, by Joca Reiners Terron, and Eles eram muitos cavalos, by Luiz Ruffato, the critics find themselves with the genre definition problem to which they belong. Classifying these novels or not is a much less important difficulty than the dilemma which they formalize or enact: the one of establishing relations, giving meaning, and having, if not totality, at least the impulse to search for it. Keywords; Bruno Zeni, Joca Reiners Terron, Luiz Ruffata.
} 
A literatura brasileira recente tem exibido algumas marcas que permitem ao crítico vislumbrar o que parecem ser linhas de força que agregam, de forma mais ou menos inclusiva, boa parte das obras.

De modo geral, nota-se na literatura finissecular e na da primeira década do século XxI uma aparente predileção pelo texto curto, avesso a classificações e pouco adequado às categorias formais pertencentes à tradição, como o conto, ou àquelas que, tendo sido num primeiro momento ruptura, hoje já se normalizaram e se constituíram, elas próprias, em uma nova tradição, como o poema em prosa.

É comum que tal embaralhamento alcance até as instâncias mais exteriores aos textos. As fichas catalográficas, por exemplo, não raro escapam dos dilemas classificatórios chamando a um conjunto de textos tão somente de "ficção".

Com alguma frequência, o elemento narrativo é mínimo, quase inexistente. Se tendem ao poema em prosa, articulam-se, porém, de tal maneira a outros textos do conjunto em que se inserem, que é difícil não se sentir a tentação de considerá-los capítulos de uma narrativa maior.

Textos breves, narrativas mínimas, conjuntos. Não bastasse a dificuldade em saber se estamos diante de um brevíssimo conto, um poema em prosa, uma descrição, um pequeno ensaio, cada texto, preservando a própria autonomia, participa ainda, de uma maneira instigante, de um conjunto. Estará o leitor diante de uma coletânea de contos, alguns deles nada convencionais? Ou será, na verdade, uma coletânea de ensaios mesclada a poemas e narrativas? Será talvez uma espécie de diário, ao mesmo tempo pessoal e artístico, no qual se misturam poemas em prosa e reflexões de caráter autobiográfico? Em alguns casos, a dúvida chega a ser se os textos, ainda que autônomos, configuram capítulos de um "romance" ou se são contos de uma espécie de antologia pessoal, ou então, quem sabe, as duas coisas ao mesmo tempo.

É por isso que, se no nível da análise de cada texto em separado, vez ou outra o crítico classificador encontra o remanso do empréstimo a outra língua de uma categoria já de si vaga ou abrangente, como o récit, ao ampliar seu olhar para o conjunto volta a um mundo no qual as etiquetas parecem não aderir mais aos objetos.

No entanto, se toco aqui na angústia do classificador, não é senão para mostrar como esses textos são desafiadores, como escapam por entre os dedos, e não para encontrar compartimentos onde encerrá-los.

\footnotetext{
* Texto originalmente apresentado em um colóquio na França em 2006, retomado e modificado para esta publicação.
} 
Desde sempre, classificar, ordenar, separar e reagrupar em conjuntos parece ter sido uma das maneiras mais básicas de o ser humano lidar com o que desconhece e com o que confronta seu entendimento ou lhe causa angústia.

E é esse impulso básico da humanidade que desmorona nessas obras, implicando toda uma nova maneira de estabelecer relações. Dizendo de outra forma, o problema do crítico classificador diante dessas obras, mais do que uma bravata de autores para com a teoria e a crítica literárias, é antes sintoma ou duplicação de um abalo ainda muito maior na própria relação entre homem e mundo, sujeito e experiência. É essa relação entre subjetividade e experiência que está colocada em xeque. Classificar ou não essas obras em categorias é uma dificuldade bem menos importante do que aquela dificuldade mesma que essas obras formalizam ou encenam: a de estabelecer relações, a de conferir sentido, a de ter, senão a totalidade - perdida já desde que as epopeias deram vez ao romance burguês -, ao menos o impulso de buscá-la.

E de que experiência, de que subjetividade estamos falando então?

Conceitos atualmente tão discutidos, que frequentam com assiduidade os ensaios e as resenhas, como o de autofiç̧ão, vêm, por sua vez, minar um pouco mais o modo de ser das relações entre mundo e sujeito; entre campo literário, reflexão filosófica e vida. Tomemos um primeiro exemplo. O fluxo silencioso das máquinas é um pequeno livro de Bruno Zeni, publicado em 2002. Nele encontram-se 44 textos, um deles de outro autor, Danilo Monteiro, na condição de "participação especial", e vários desenhos dos artistas plásticos Ana Luiza Dias Batista, Cláudio Spínola, Flavia Yue e João Paulo Leite. Alguns desses textos foram primeiramente publicados em revistas literárias, separados ou em pequenos conjuntos aos quais não se obedeceu na reorganização em livro. Todos foram escritos mais ou menos no mesmo período e versam, principalmente, sobre a cidade, ou as relações que se estabelecem na cidade - facilmente identificável com São Paulo, mas nem por isso apenas vinculáveis a ela. Outro traço perceptível, e que aproxima esta a outras obras do período, é a presença do ready-made, recurso que nada tem de novo, desde que surrealistas e dadaístas o colocaram na ordem do dia da criação artística, mas que, retomado no contexto dessa produção brasileira recente, estabelece uma espécie de "sobreproblematização" da questão das categorias estáveis, das percepções confiáveis, das divisões fixas, uma vez que é, no nível dos recursos e procedimentos, um desdobramento, um espelhamento do problema maior que parece presidir a estruturação dessas obras: um mundo que desestabiliza a forma e o olhar do leitor.

Assim, o bordão de um conhecido programa de rádio, voltado à classe média paulistana, que apresenta músicas entremeadas a notícias sobre o trânsito na cidade de São 
Paulo na hora do rush - "você liga pra cá e conta seus caminhos por São Paulo" -, adquire um sentido muito além do literal e parece sintetizar os percursos do livro. Mas esses caminhos pela cidade não levam a parte alguma, não constituem trajetórias em direção a algo. Não são, por outro lado, a flanêrie, andanças que se completam em si mesmas. São um acumular contínuo, um amontoar que nada cria, não constrói, não destrói, não esvazia nem preenche de substância.

A escolha, em quase todos os textos, da primeira pessoa, bem como a existência da "Faixa escondida", que fecha o livro e traz uma mistura de enumerações, tempos, pessoas, dados biográficos do autor, agradecimentos, configuram a possibilidade de ver nesse livro uma autoficção.

"Faixa escondida" está impressa em fonte de tamanho menor que os demais textos e se apresenta no sentido invertido do papel, obrigando o leitor a colocá-lo na horizontal. O que poderia parecer uma forma de esconder esse texto na folha de papel acaba, ao contrário, chamando mais a atenção para si. A palavra "faixa" parece remeter ao universo musical, onde é uma espécie de bônus em um CD ou DVD. Esse caráter de elemento extra e extraordinário parece, ambiguamente, querer passar-se por algo de menor importância ou exatamente seu oposto, aquilo que se destaca. Dessa maneira, o elemento autobiográfico reorganiza a leitura que, é bom lembrar, não requer que o leitor siga necessariamente a ordem em que os textos se apresentam. Mescla de ficção, ensaio, poemas em prosa, pequenos contos e autobiografia, esse livro remete, num primeiro instante, ao universo da formação, da Bildung. É inevitável se pensar no modelo do romance de formação uma vez que neste, segundo o paradigma proposto por vários autores, como Moretti e Lukács, a estrutura da biografia ou autobiografia é imprescindível, já que se trata de um desabrochar integral da personalidade no embate com a ordem social. No caso em questão, a estrutura autobiográfica parece estar mantida, mas já não é mais possível saber que subjetividade é essa que organiza o texto, visto que não se trata de uma instância dada, estabelecida ou instável. Ambígua, ela pode ser criação ficcional de uma voz, de um personagem, ou então autoficção - quase todos os textos são em primeira pessoa, que não trata de si, mas da cidade ou do trânsito pela cidade.

Contudo, se no livro de Zeni a formação subsiste ou se insinua, ela é mais desejo do que processo em andamento. Na "Faixa escondida", aproximada aos demais textos, percebe-se o sair da casa dos pais, a experiência amorosa, a relação com o mundo, mas nota-se que tudo, de alguma forma, está "submetido" à cidade. É no contato com ela que tudo se coloca, muitas vezes como impossibilidade ou dúvida ("Você liga pra cá e conta como se ama em São Paulo", p. 62, diz o narrador, apropriando-se 
do bordão do programa de rádio já mencionado); hesitação ou gesto no vazio que se esgota em si sem que algo surja daí - cito como exemplo o texto "O salto do menino" (p. 19), que descreve o menino de rua no momento em que salta a grade que separa a calçada da rua do corredor de ônibus.

Nesse texto, um pequeno conto, há uma espécie de esforço épico degradado. Impulso "heroico", "travessia", que, ainda que ligado à sobrevivência (rua) e até a algo de lúdico (como a brincadeira infantil do pula-sela), esvazia-se de sentido, esgota-se em si, não redundando em nenhuma conquista épica. O que resta disso está na dimensão interna, individual, porém de um ser não individualizado, não singularizado. O que fica é uma experiência interna, mas uma experiência que é cicatriz do que foi feito.

É conquista ("Segundos pairando no ar"), é sensação de liberdade ("O vento nas vestes"), é dor ("O fogo nas solas dos pés"). Porém, em nada redundará aquilo que em vez de sabedoria vem nomeado como cicatriz - nem para o menino, nem para o olhar que o observa.

Não é a cicatriz de Ulisses. A cicatriz deixada pela batalha.

Há uma gratuidade nessa "batalha" com a cidade. É um enfrentamento da cidade (pular a grade do corredor de ônibus em vez de obedecer a ela). Mas é esse um combate aprendido e vencido? Cicatriz gloriosa ou experiência sem "progressão"? Antes que formação propriamente dita, há o acúmulo de impressões, gestos, um amontoar-se que parece mais possível que um formar-se. Ou uma "formação" que no máximo consegue ser um amontoado em trânsito (fluxo).

A palavra "acumulação", em português, vem definida nos dicionários como um amontoamento, um ajuntamento, uma sedimentação, uma designação genérica do trabalho constitutivo das águas correntes. Acumular é reunir(-se) ordenada ou desordenadamente, é colocar em montão. ${ }^{1}$

No texto "O salto do menino", a experiência parece fadada ao aspecto mais exterior da aventura degradada, em escala mesquinha, sem levar para além de si mesma.

É da mesma natureza o que ocorre no livro Curva de rio sujo (2003), de Joca Reiners Terron, um dos mais interessantes surgidos no período.

O livro vem sendo tratado pela crítica como uma coletânea de contos marcada pela autobiografia do autor. São textos independentes, às vezes próximos do modelo do conto, em alguns casos dentro mesmo da forma consagrada por Edgar Allan Poe. Remetem à forma poética ou à prosa poética e formam um conjunto no qual, mais

1 Trata-se, aqui, tão somente do vocábulo e não de conceitos os quais ele nomeia sob as mais diversas óticas, como a marxista.

168 - HOSSNE, Andrea Saad. Acumulação e desestabilização da forma na narrativa 
do que uma coletânea, se tem um percurso que vai da infância à idade adulta, cada qual correspondendo a uma das duas partes da obra. É um conjunto articulado, passando pela memória, pelo rio (em geral, o Apa), pela família, por cidades e um quase leitmotiv que é a falta ou a precariedade da visão.

Há com frequência um foco narrativo em primeira pessoa que não se autodenomina e que às vezes não sabemos se é sempre a mesma ou se é outra - isto é, se é pessoa gramatical ou se é um narrador constituído - embora as "Notas" ao final do livro apontem mais nessa segunda direção, com a presença maciça da autorreferência.

O campo da autoficção se abre novamente. E mais uma vez, embora aparentemente os textos possam ser, quase todos, enquadrados mais ou menos confortavelmente na rubrica de conto, o conjunto estabelece uma dialética peculiar com as partes. A articulação entre eles é tão cerrada que o leitor pode pensar, sem qualquer dificuldade, que se trata de capítulos e que a obra é um romance. Mas como também pode, ao mesmo tempo, tomá-lo como uma coletânea de contos mais ou menos reconhecíveis como tal, com uma temática comum, e que podem ser lidos em ordem diversa daquela em que se apresentam no livro, resulta daí uma desestabilização de seu olhar, nascida dessa desestabilização da forma, para a qual o procedimento de acumulação muito contribui. Não se trata do jogo, do princípio estruturador de uma Rayuela de Cortázar. Esse elemento, dado já no título da obra do autor argentino, sequer parece ser considerado em Curva de rio sujo. Neste, a acumulação vem dada já pela maneira como a memória é concebida, o que se percebe no título e na epígrafe - "Curva de rio sujo só junta tranqueira" - advinda de um provérbio popular.

Se a memória é um rio, tal como reza o topos literário e filosófico, ela aqui é um rio sujo - o que pode ter a ver tanto com a mescla entre ficção e biografia, a autoficção, quanto com a concepção de que a memória jamais é límpida. Nesse rio sujo, o que ocorre é o amontoar, o juntar, o acumular. E o que se amontoa ou acumula são tranqueiras, termo bastante coloquial que significa tanto o que não tem importância alguma, quanto o que não serve para nada ou é resíduo, lixo, detrito.

Que experiência de vida, que experiência com o mundo é essa? Que subjetividade se forma assim? Ou seria mais lícito se falar de um acúmulo de impressões, memórias, gestos que talvez não sirvam mesmo para nada e de uma subjetividade que é mais amontoar-se do que um formar-se, uma construção?

E a acumulação, que pode, portanto, ser vista como a experiência possível e o mais próximo a que se pode chegar de ser um sujeito, é ela própria o princípio estruturante que formaliza essa crise da experiência e da subjetividade, já que também por acúmulo se faz a leitura das partes/capítulos do livro. 
Em Eles eram muitos cavalos (2001), de Luiz Ruffato, como nas duas obras anteriores e em várias outras do mesmo período, a temática da degradação urbana também se formaliza numa dialética insólita entre textos/partes e o todo/conjunto. $\mathrm{E}$ aqui também não se trata de um abandono puro e simples das categorias formais consagradas, mas de uma necessidade interna da obra. Diante dos diversos ready-made, das variações de registros linguísticos, das colagens que o texto congrega, da dúvida se os vários textos são fragmentos que ambicionam a superposição em busca do efeito de simultaneidade ou se são coletânea de poemas em prosa, contos, cenas etc., o leitor busca um eixo unificador.

O que parece funcionar como eixo organizador dos textos, enquanto conjunto, numa forma, ainda que ruinosa, de romance, parece ser o tempo (a data 9 maio 2000, do início à madrugada do dia 10), o espaço (São Paulo), o enredo (a vida na cidade), a personagem (pela terceira vez, a cidade).

Cidade, então, mais do que tema e do que espaço, papéis a ela tradicionalmente dedicados, é também personagem, mas não sob a forma da personificação, aos moldes dos modernistas de primeira hora, como a Pauliceia de Mário de Andrade. A cidade-personagem coloca em foco a sociabilidade e, com ela, sua violência constitutiva, que permeia todas as relações, não apenas sob a forma explícita do crime - violência que é, pois, uma espécie de elemento unificador da narrativa, mesmo aquela que nem sempre é visível num primeiro olhar. Ao fazê-lo, ao focalizar a sociabilidade, ainda que profundamente vinculada à cidade de São Paulo, a narrativa ultrapassa-a, dando conta do fracasso do projeto de modernização do país. O enredo, portanto, não trata da vida da cidade, mas da vida na cidade. É assim que, mais do que espaço, mais do que personagem, mais do que tema, a cidade é antes de tudo as relações que nela se estabelecem: a sociabilidade na cidade é a história mesma que se conta no livro, de tal forma que a escolha por um único dia não é simples imitação de um modelo joyceano, ou um "maneirismo" contemporâneo qualquer, mas, como já dito, necessidade constitutiva da obra. Por meio de colagens, de simultaneidade e de acumulação, é a própria degradação urbana que se constrói diante do leitor.

É, pois, por acúmulo que a sociabilidade e com ela o texto se constituem. Os conceitos vizinhos de formação e montagem não parecem dar conta do que se passa nesse livro e em muitos de seus contemporâneos brasileiros. E esses conceitos, um numa chave mais tradicional, outro na via das rupturas da modernidade, amparavam a ideia mesma de uma longa narrativa, da experiência do romance até bem recentemente. Se, ainda quando se trata de um eixo com caráter de individuação, ou mesmo personalização, nos moldes da atualmente tão recorrente "autoficção", esta é mais um

170 - HOSSNE, Andrea Saad. Acumulação e desestabilização da forma na narrativa 
acumular desordenado de experiências do que um processo formativo que leve a um desabrochar integral da personalidade, em casos em que a individuação está ausente do texto, como em Eles eram muitos cavalos, já não se trata, por outro lado, da montagem, ou do conjunto de metáforas individuais que se agrupam sem uma necessidade lógica, para manter como esteio as formulações de Eisenstein - base de toda teoria da montagem, seja ela em cinema ou em literatura - pois que a montagem implica a ideia de combinação e pressupõe, ainda que liberta da linearidade do discurso, uma "representação perfeitamente acabada", uma "justaposição de blocos".2

Justaposição de blocos e junção de imagens não são da mesma natureza da acumulação. Pressupõem um ordenamento que não é condição para a acumulação. Amontoar implica se não a precariedade em si mesma, decerto a sensação e a experiência do precário, que não se confunde, por sua vez, com o fragmento e o simplesmente inacabado. $\mathrm{O}$ amontoado é uma estrutura em si, que parece abrir-se como arena, num movimento coletivizante (seria, assim, parte de algo que poderia ser chamado de "romance arena"3).

Acumulação e desestabilização da forma mostram-se, portanto, vias das mais produtivas na literatura brasileira contemporânea, rendendo obras as mais diversas, todas, porém, repondo, o tempo todo, na crise da representação, as crises maiores da experiência e da subjetividade.

Sem qualquer pretensão de ser exaustiva, tanto no corpus quanto na articulação crítica, essa observação rente ao texto abre um viés para a reflexão sobre essa literatura brasileira recente. Segui-lo é tarefa ampla, projeto que implicará o enfrentamento da problemática que se delineia quando do vocábulo "acumulação" pode-se chegar a um conceito, e a descrição do procedimento literário pode levar a vertentes do pensamento moderno e contemporâneo em âmbitos que não se restringem ao literário.

Andréa Saad Hossne é professora de Teoria Literária e Literatura Comparada na Universidade de São Paulo. É autora de Bovarismo e romance: Madame Bovary e Lady Oracle (Ateliê, 2000).

2 Essa leitura da montagem deriva daquela a que procede Modesto Carone ao analisar a obra de Trakl em Metáfora e montagem. São Paulo: Perspectiva, 1974.

3 Apenas menciono essa proposta conceitual aqui, desenvolvendo-a alhures. 